\title{
The Role of Urgency in Forming Cross-Sector Collaborations to Address Environmental Sustainability in the U.S.
}

\author{
Mark Heuer ${ }^{1}$ \\ ${ }^{1}$ The Sigmund Weis School of Business, Susquehanna University, United States \\ Correspondence: Mark Heuer, The Sigmund Weis School of Business, Susquehanna University, United States. \\ E-mail: heuerm@gwu.edu
}

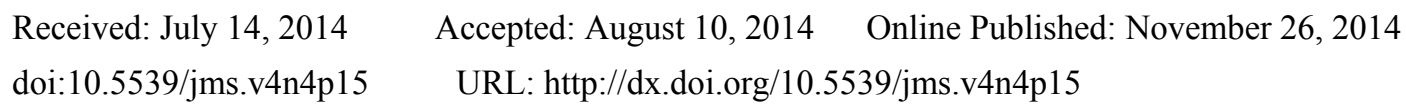

\begin{abstract}
Recognizing that the U.S. has failed to formulate and implement an integrated national strategy addressing environmental sustainability and energy conservation, this paper proposes cross-sector collaboration among the business, government, and nonprofit sectors as a necessary approach. This paper draws on institutional theory to explain differences among the sectors, and the challenges posed in forming cross-sector collaboration. Scenarios of sustainability initiatives are presented along with potential inhibitors to explain barriers posed by inter- and intra-sector institutional differences. This paper proposes that prolonged urgency, supported by ongoing turbulent conditions economically, socially, and environmentally, is necessary to form cross-sector collaboration at a supraorganizational level.
\end{abstract}

Keywords: cross-sector collaboration, environmental sustainability, government, institutional theory, non-profit organizations, private sector organizations, urgency

\section{Introduction}

Why has the U.S. failed to formulate and implement an integrated national strategy addressing environmental sustainability and energy conservation? This question is being asked again with hydraulic fracturing making the U.S. a global leader in natural gas production, despite hazardous consequences environmentally and socially.Additionally, to accommodate record increases in natural gas hydraulic fracturing, LNG (liquefied natural gas) plants are being retrofitted to export LNG to Asia and Europe, when a decade ago these plants were constructed to import LNG into the U.S.

An historical context provides a useful framing for understanding U.S. energy and environmental policy, or lack thereof. For more than 40 years, the U.S. has faced severe consequences and repeated warnings about energy and the environment. The economic impact of the OPEC energy crisis in the 1970's - not to mention gasoline rationing and long waits in gas lines - failed to engender lasting change. This failure occurred despite significant efforts, such as the Carter Administration's comprehensive energy legislation in the late 1970's, which addressed energy conservation and provided subsidies for developing renewable sources of energy. The Carter energy legislation dissolved after referral of various component parts to congressional committees, where special interests successfully pursued a divide and conquer lobbying strategy. This legislative failure typifies the inability of broad-based cross-sector level efforts to address complex problems despite dire economic, social, and environmental outcomes. The lack of continuity in government, the rising influence of corporate special interests as a result of 1970's era political action committees being established, and conflicting agendas among nonprofit organizations have rendered prolonged cross-sector efforts at a supraorganizational level frustratingly fruitless.

The purpose of this paper is to analyze theoverall lack of success to achieve environmental sustainabilityand to discuss the importance, as well as the challenges involved, informing cross-sector structures with the scale to implement sustained strategies to achieve positive outcomes. In this paper, I discuss various scenarios contributing to the failure of cross-sector efforts to address the energy and environmental crises now in its fifth decade in the U.S. However, it is noteworthy that there have been, and likely will continue to be, examples of successful cross-sector effortsin supportof sustainability, energy efficiency, and renewable sources of energy on a smaller scale. Government at all levels has proposed, developed, and implemented programs to improve energy efficiency through tax incentives, grants, and direct investments. Examples include government tax incentives for purchasing hybrid vehicles, as well as tax credits for solar and wind power, which has greatly assisted those 
industries in achieving impressive, if inconsistent, growth in recent years. Corporations, such as DuPont, have embraced sustainability and formed multiple partnerships with environmental groups. Nonprofit environmental groups, such as the Chesapeake Bay Foundation (in partnership with federal, state, and local governments), have scored recent legislative victories in securing funds to address crucial clean water needs.

However, given the scale, complexity, and urgency of the energy and environmental sustainability challenge, the lack of cross-sector collaboration at a supraorganizational level significantly limits U.S. energy and environmental policy implementation. Supraorganizational systems of collaboration are loosely coupled, multilayered networks of referent organizations (Trist, 1983) designed to take voluntary initiatives toward solving a shared social problem (Pasquero, 1991). Supraorganizational collaboration aims at solving "metaproblems" (Trist, 1983), or multi-layered problems, cutting across entire societies.

This paper posits that while cross-sector collaboration at the supraorganizational level is an appropriate and much-needed mechanism for addressing environmental sustainability and energy conservation, it is unlikely that these twin challenges will be addressed successfully and sustainably through cross-sector collaboration without prolonged urgency. In order to develop this argument, I have utilized hermeneutic interpretation (Cassell \& Symon, 1994, p. 150) to identify thematic clusters from historical phenomena which have occurred repetitively over the decades since the 1973 energy crisis. Table 1 identifies examples of these phenomena in which crises occur, causing a flurry of action, only to subside until the next crisis occurs.

Table 1. U.S. responses to energy crises since 1973

\begin{tabular}{|c|c|c|c|}
\hline Crisis Situation & Nature of Turbulence & Urgency & Result \\
\hline $\begin{array}{l}\text { 1973. OPEC Oil } \\
\text { Embargo. }\end{array}$ & $\begin{array}{l}\text { Fuel shortage and uncertain flow } \\
\text { of supply; Price controls; } \\
\text { Economic recession; high inflation }\end{array}$ & $\begin{array}{l}\text { Gasoline lines; rapid price increases in } \\
\text { gas from } 30 \notin / \text { gallon to } \$ 1.20 / \text { gallon. }\end{array}$ & $\begin{array}{l}\text { Stock market drops } 45 \% \text {; oil stocks } \\
\text { perform well; Trans-Alaskan pipeline bill } \\
\text { becomes law; U.S. announces Project } \\
\text { Independence to promote energy } \\
\text { independence. Oil imports increase. U.S. } \\
\text { economy slips into deep recession. }\end{array}$ \\
\hline $\begin{array}{l}1976 . \quad \text { Carter } \\
\text { Administration } \\
\text { Energy Policy. }\end{array}$ & $\begin{array}{l}\text { Economic recession and high } \\
\text { energy costs roil U.S. economy. }\end{array}$ & $\begin{array}{l}\text { Foreign policy, national security, and } \\
\text { energy issues shake confidence of U.S. } \\
\text { citizens and institutions. }\end{array}$ & $\begin{array}{l}\text { Carter Administration proposes windfall } \\
\text { profit tax to fund alternative fuel } \\
\text { development; Carter energy policy largely } \\
\text { not enacted by Congress. }\end{array}$ \\
\hline $\begin{array}{l}\text { 1979. Iranian oil } \\
\text { shutdown. }\end{array}$ & $\begin{array}{l}\text { Economic stagflation; Uncertainty } \\
\text { of oil supply from OPEC } \\
\text { countries. }\end{array}$ & $\begin{array}{l}\text { Renewed concerns about fuel shortages; } \\
\text { Spike in gas prices. }\end{array}$ & $\begin{array}{l}\text { Profound influence on U.S. foreign policy } \\
\text { and national security policy. Economy } \\
\text { worsens. }\end{array}$ \\
\hline $\begin{array}{l}\text { 2008. Gas prices } \\
\text { reach } \$ 4 / \text { gallon. }\end{array}$ & $\begin{array}{l}\text { Economic recession becomes } \\
\text { imminent; Consumer spending on } \\
\text { non-fuel items declines sharply. }\end{array}$ & $\begin{array}{l}\text { Widespread anxiety due to crude oil } \\
\text { prices increasing } 40 \% \text { in six months. }\end{array}$ & $\begin{array}{l}\text { Major industries (auto, airlines, travel) face } \\
\text { rapid revenue declines; GM and Chrysler } \\
\text { file for bankruptcy and require } \\
\text { multi-billion dollar bail-out; Crude oil } \\
\text { reaches } \$ 138 / \text { barrel; Oil profits soar. }\end{array}$ \\
\hline
\end{tabular}

As suggested in Table 1, ongoing, significant turbulence, involving economic, social, and environmental factors, is a necessary, but not sufficient, condition for the prolonged urgency necessary to bring about integrated, sustained focus on energy policy. Cross-sector coordination and commitment are vital components of such an effort. However, managing deeply engrained cultural differences and trust issues among the sectors requires a sustained focus to succeed in forming the collaboration. In the U.S., the September 11 terrorist attacks led to the successful formation of cross-sector collaboration at a supraorganizational level; however, this has not been replicated in the energy and environmental arenas.

In this paper, I discuss the challenges in forming lasting cross-sector collaboration by discussing institutional differences among the sectors. An overview of previous cross-sector efforts at various organizational levels is provided, followed by a discussion of sectoral differences based on institutional theory and macroculture. This is followed by scenarios identifying policy initiatives and potential inhibitors that can result from incomplete or faulty efforts in forming cross-sector collaborations. The role of mediating structures and related mechanisms are then introduced to discuss approaches for forming sustainable cross-sector collaborations. The paper concludes by discussing the role of urgency and turbulence as factors that influence successful forming of cross-sector collaborations. Hermeneutic interpretation is utilized to interpret the significance of discussions, debates, and editorials in the context of U.S. energy and environmental policy and institutional theory (Radnitzky, 1970). 


\section{Literature Review}

Cross-sector partnerships can be defined as efforts "formed explicitly to address social issues and causes that actively engage the partners on an ongoing basis" (Selsky \& Parker, 2005). Conceptually, cross-sector collaboration is the structure which, if formed and maintained successfully, could support implementation of a national energy and environmental policy and strategy. Googins and Rochlin (2000) suggest that most of the major issues confronting our society require strong cross-sector partnerships, given the shifting roles and relationships of private and public sectors across the globe. However, institutional theory provides an explanation for why the differing cultures of the private, government and nonprofit sectors make it difficult to form such collaborations.

Organizations in every sector face changing pressures and evolving public expectations that encourage them to collaborate across sectors (Selsky \& Parker, 2005, p. 850). Googins and Rochlin (2000, p. 128) suggest that cross-sector collaboration presents the opportunity to combine the unique capabilities and resources of each party to deliver outcomes beyond what any one sector can achieve. However, Waddock (1988, p. 19) suggests that a reason for the demise of cross-sector collaborations is the failure to understand that these relationships are cooperative, interactive entities that require ongoing commitment on all sides. In general, where cross-sector formation has succeeded in the energy and environmental arenas, it has been at the individual program level. Starik and Heuer (2002), for example, analyzed cross-sector formulation and implementation of environmental initiatives involving specific programs, such as the EPA's Green Lights Program and Low-Income Weatherization. In sum, while organizational leaders perceive the importance of forming cross-sector efforts at the supraorganizational level, cultural, control, and trust issues remain as barriers.

\section{The Institutional Context of Cross-Sector Collaboration}

Collaboration can be defined as a "process through which parties who see different aspects of a problem can constructively explore their differences and search for solutions that go beyond their own limited vision of what is possible" (Gray, 1989). Collaboration is most likely to occur when problems are complex, wide in scope, and beyond the means of single organizations to solve unilaterally (Trist, 1983). Waddock (1991) refers to these "problem domains" as "indivisible problems" which, as a result, require the efforts of organizations in two or more sectors in a forum in which they cooperatively attempt to solve a problem or issue of mutual concern that offers identifiable benefits for all participants, either directly or indirectly.

Googins and Rochlin (2000) suggest that there appears to be more forces working against partnerships than promoting them, including natural obstacles such as different languages, cultures, goal orientations, and values, all of which are indicative of the complexity of cross sector relationships and the inherent difficulties in achieving them successfully.

These obstacles can be framed through institutional theory (DiMaggio 1983; DiMaggio \& Powell, 1983; Scott \& Meyer, 1983; Meyer\& Rowan, 1977). In response to conditions of uncertainty, organizations isomorphize toward prevailing practices and procedures in their institutional context. Organizations may isomorphize towards the behavior of other organizations in their industry or sector through a "taken for granted" adoption of commonly accepted practices and behavior.The result is a bureaucratization that makes organizations in the same institutional context more similar without necessarily making them more efficient (DiMaggio \& Powell, 1983).

Additionally, the leadership of similar organizations can be described as participating in interorganizational macrocultures, which can be defined as the "relatively idiosyncratic, organization-related beliefs that are shared among top managers across organizations" (Abrahamson \& Fombrun, 1994). These linkages, or value added networks, form based on cooperative and competitive tendencies, leading to shared beliefs, cohesiveness, and organizational inertia regarding innovation and change. Organizations may change their goals or develop new practices, but in the long run, organizational actors tend to construct an environment around them that constrains their ability to change (Scott \& Meyer, 1983). In essence, the rise of an elaborate institutional environment stabilizes external and internal relationships and buffers organizations from turbulence (Emery \& Trist, 1965).

Unique characteristics of interorganizational macrocultures exist in all three sectors: business, government, and nonprofits. As the following discussion suggests, cross-sector partners may have "fundamentally different governance structures and missions" (Rondinelli \& London, 2003) and "differing motivations, rewards, and compensation systems" (Blois, 2004). Thus, the institutionalized context of each sector, and the challenges they present, are important to explore in terms of intercultural dynamics (Parker \& Selsky, 2004) and cross-sector collaboration. 


\subsection{Businesses}

Institutional theory and research on macrocultures suggest that top managers become focused on set approaches and beliefs, thereby reinforcing previously established structures of cooperation and competition.In terms of cross-sector cooperation in support of an integrated approach towards environmental sustainability, macrocultural homogeneity presents clear disadvantages in that it influences collective inertia, technological traditionalism, and strategic similarity (Abrahamson \& Fombrun, 1994).

Not all businesses in a sector exist in macrocultures. Entrepreneurs, for example, may have unique microcultures and possess ideas and innovations that diverge from institutionalized practices of larger players in the same industry. However, in a highly institutionalized context in which powerful stakeholders, such as government, may be interconnected with large industry macrocultures, innovations may never achieve the needed scale and scope to be market forces because of a lack of access to the powerful stakeholders that join with large firms to form the dominant macroculture of an industry.

\subsection{Nonprofits}

Given the absence of the profit motive, nonprofits often exhibit "other-regarding" behavior. This may involve providing a public good based on moral principle, even if doing so may be contrary to organizational self interest. This altruistic, or "other-regarding," behavior of nonprofits can be multi-faceted (Grimalda \& Sacconi, 2005). For example, an element of the nonprofit macroculture may be the pursuit of ideological beliefs as an end in itself, rather than specific actions that may further the social good. Knox and Gruar (2006) observe that nonprofits often pursue multiple, non-financial objectives and face a bewildering array of dilemmas, as they deal with interacting and recurring stakeholder pressures. The values of most environmental groups involve decision by consensus, love of nature, conservation, and anti-consumerism (Westley \& Vredenburg, 1991). Along with the often unique values-based nature of nonprofits, their varied social missions, and their diverse, dynamic stakeholder relationships, the nonprofit sector (specifically, environmental groups) is often "thinly institutionalized" (Westley \& Vredenburg, 1991). They also tend to be loosely structured and lack a developed internal hierarchy and central authority.

This structure often inhibits collaboration and, as a result, "agreements between environmentalists and business are often rejected by environmental groups" (Westley\& Vredenburg, 1991). Long and Arnold (1995) note that there is often an "intense rivalry" among environmental nonprofit groups operating in similar issue areas and competing for a fixed pool of resources. Additionally, many environmental nonprofits are more focused on their own existence rather than institutional norms [at the sector level], as they deal with adapting to environmental uncertainty [policy environment], problematic interdependencies [varied stakeholder pressures and interests] and managing resource flows [i.e., service and budget maximization] (Hewitt \& Brown, 2000). Many nonprofit environmental organizations were founded on the principles of fighting the offenses of corporations and the intrusions of government. When nonprofits tap into the potential of partnerships, they risk compromising either their independence or their ability to maintain the public's trust (Long \& Arnold, 1995).

\subsection{Governments}

Ring and Perry (1985) note that the separation of power (federal, state and local executive branches, more than one legislative body and a variety of judiciaries) in government sharply divides the policy formulators from the policy implementers. This division, as well as the greater openness of government to external environments (e.g., constituent access to legislators, who are the strategy makers), largely defines the macroculture of government .Policy formulators and implementers must deal with a wide range of stakeholder interests, which may be divergent and, thus, difficult to reconcile (Ring \& Perry, 1985). As a result, public policies may be purposely ambiguous or contain multiple goals that may not be compatible.

Additionally, Scott and Meyer (1983) note that the administrative structures of governmental agencies operating within a given policy area tend not to be simple, lean, "rational" bureaucracies, but relatively complex, competing, and overlapping systems. Scott and Meyer (1983) refer to Downs (1967) in noting the "leakage of authority" as programs designed by politicians move down into agencies staffed by career civil servants and, more generally, as programs must attempt to obtain the support of diverse collections of officials with varying goals and interests.

Meanwhile, a diffusion of power has occurred in Congress with the declining importance of seniority and a shift in emphasis from committee chairs to subcommittee chairs. As a result, in the modern era, policymaking (formulation) has become more decentralized (Ornstein, Peabody \& Rhode, 1981) and many policy fiefdoms have evolved where previously a few powerful committee chairs could control the issue agenda. As noted 
previously, the Carter Administration's energy plan was split into as many as thirty different sections due to committee and subcommittee jurisdictions.

Additionally, policy proliferation at the state level on environmental issues adds complexity to formulating and implementing strategy.

\section{Formation Challenges of Cross Sector Collaboration}

The scenarios involved in delaying or blocking cross sector collaboration are nearly unlimited and certainly greater than the scenarios leading to successful, ongoing cross sector collaboration. The scenarios described below attempt to illustrate the difficulty of forming cross sector collaboration given institutional and other factors.

Government initiates/Government inhibits. Government has the constitutional prerogative to introduce legislation and implement regulations. However, turf battles based on competing interests in legislative and executive branches can result in legislation and regulations stalling or becoming diluted with competing or irrelevant provisions.

Business initiates/Government inhibits. Business may develop a technology or capability that can address environmental concerns with a market-based approach. Government can inhibit by imposing command-control regulation rather than adapting a market-based approach.

NPO's initiate/Government inhibits. NPO's may initiate an environmental agenda at the beginning of a congressional session that represents broad agreement among NPO's. Government may inhibit this effort by responding to competing special interests and approach the issue with incremental responses in order to balance political interests.

Government initiates/Business inhibits. Government appropriates funding for basic R\&D research on renewable energy sources. Business inhibits this initiative by being unwilling to undertake the risk of commercialization due to a short-term profit focus and uncertainty about market demand.

Business initiates/Business inhibits. A Strategic Business Unit may develop an innovative technology, which could lead to the commercialization of a renewable energy product. Business may inhibit the research because of the long lead-time in development, the high risk of failure, and the short-term focus of senior management.

Nonprofits initiate/Business inhibits. NPO's may develop a communication plan to educate targeted businesses in certain industries on sustainability opportunities. Business may inhibit this effort because the NPO's are not considered a primary stakeholder of their firm or their industry.

Government initiates/Nonprofits inhibit. Congress and a newpresidentialadministrationmay introduce a sustainability agenda that includes a mix of regulation and market-based approaches. An ad-hoc coalition of nonprofits mounts a media campaign against the market-based provisions, resulting in legislative gridlock of the entire agenda.

Business initiates/Nonprofits inhibit. Business identifies a recycling strategy that can be profitable and good for the environment. A coalition of nonprofit organizations mounts a lobbying campaign to oppose "big business" involvement in the recycling strategy, calling it a "green wash" public relations effort designed to cover up past environmental indiscretions. The recycling strategy stalls.

Nonprofits initiate/Nonprofits inhibit. An ad-hoc coalition of environmental nonprofit organizations advocates an initial draft of legislation that addresses the specific interests of their coalition members and stakeholders. However, when the bill is introduced, individual nonprofits lobby various provisions in the bill that relate to their organization's specific focus. The lobbying activity causes confusion among legislators, and the carefully crafted legislation splinters due to the advocacy of nonprofit special interests. Therefore:

Proposition 1: The formation of cross-sector and intra-sector initiatives is inhibited by the difference among, and within, the business, government and nonprofit sectors in terms of institutional culture, motivations, and desired outcomes.

Missing from the above scenarios is a boundary-spanning mechanism or group to facilitate the interests, cultural differences, and communication among the cross-sector participants. Googins and Rochlin (2000) note that as "the level of engagement required for a strategic partnership rises, so does the level of complexity in its management.... However, few representatives from any of the sectors possess background in building and maintaining cross-sector partnerships." Traditional hierarchical governance methods are frequently unsuccessful in these situations, as Bertels and Vredenburg (2004) note that attempts by individual organizations to solve problems that affect multiple parties are "often uncoordinated and can even cause unanticipated problems for 
other stakeholders." Thus, to address the complexity of these relationships, a distinguishing feature of cross sector partnerships is the frequent presence of bridging organizations to convene or manage cross-sector collaborations (Pasquero, 1991; Westley \& Vredenburg, 1991). Bridging organizations are central to the emergence of functional networks that span or link organizations into value-added chains (Trist, 1983; Emery \& Trist, 1965). Conceptually, any collaboration can be considered a bridge, in the sense that by definition the bridging process connects entities previously considered separate. It is helpful, however, to define bridging as a distinctive configuration of collaborative negotiation related to, but separate from, such entities as a multiparty collaboration, joint ventures, strategic alliances, and mediations (Westley \& Vredenburg, 1991).

Gray (1989) expounds on the importance of a boundary-spanning entity with a set of critical success factors regarding formation, as follows:

(a) A mediating organization that can reconcile conflicting values and interests before action can take place,

(b) A legitimizing convener transcending sectoral interests,

(c) Joint stakeholder ownerships of decisions, and

(d) Collective responsibility for future actions.

Bridging organizations enter collaborative negotiations to forward their own agendas, as well as to serve as links among domain stakeholders. In essence, bridging organizations act as both broker and agent in the problem domain as they engage in the incremental creation of a negotiated order that may permit greater collaboration among all stakeholders (Westley \& Vredenburg, 1991). In order to create an environment for a sustainable collaboration, the diverse interests of the various parties must be addressed. Rondinelli and London (2003) found that participants should be able to specify profit and environmental outcomes, as well as identify results that can be monitored and measured after solutions are applied. Another critical factor affecting successful formation of a collaborative effort is the belief that sustainability issues are beyond the ability of one sector to address and, that through interaction with other sectors, a needed solution may be possible (Waddock, 1988).

Collaboration is essentially a network of ongoing interactions, not a structural relationship between two monolithic cultures. As such, the formation of cross-sector collaborations involves "an emergent culture approach which highlights the active, negotiating work of boundary-spanning" entities who manage the collaboration, serve on task forces and committees that implement the partnership's project, and deal with issues as they come up over time (Emery \& Trist, 1963). It is the process of negotiation that helps the participants in collaboration "transcend a priori differences. Hence, negotiated practices, rather than shared practices and shared values, are at the core of an emergent culture" (Emery \& Trist, 1963). In sum, formation of cross-sector collaboration at the supraorganizational level requires that stakeholders integrate the perspectives of their "adversaries" into their own rationales. For this reason, supraorganizational systems of collaboration are necessary in order to form an effective collaboration on a societal level problem, such as environmental sustainability.

At the supraorganizational level, Pasquero (1991) posits that three interrelated levels of learning are required:

At the individual level, each person must learn interpersonal skills (how to collaborate), technical skills (how to combat environmental deterioration), and social psychological (how to modify one's mind-set and habits permanently). At the organizational level, organizations must strive to overhaul their decision-making structures and practices. At the collective level, collectivities must appropriate new knowledge and new techniques. Societal learning is a complex process involving several types of transfers among individuals or communities: transfers of technology, expertise, and innovations. These transfers must occur vertically (between social levels) and laterally (among peers).

Pasquero (1991) concluded that research is still scarce on these issues of learning, which are crucial for the success of large-scale collaboration. The relative scarcity of literature on the formation of cross-sector collaboration since 1991 supports this point of view.

\section{Environmental Factors: Urgency and Turbulence}

Another important contribution of bridging organizations is that they are essential to establishing the cooperative links that help stabilize turbulent environments (Emery \& Trist, 1965; Trist, 1983). Turbulent environments require some relationship between dissimilar organizations whose fates are, basically, positively correlated (Westley \& Vredenburg, 1991). Thus, institutionalization through cross-sector collaboration on environmental sustainability becomes a necessity in order for a "selection of goal paths that offer a maximum convergence regarding the interests" of other sectors and organizations (Westley \& Vredenburg, 1991). 
As well-intentioned as the various policies of tax subsidies for renewable sources of energy and hybrid automobiles, investments in public transportation, and corporate "greening" may be, the fact remains that the U.S. has not developed a sustained, societal level focus on environmental sustainability and energy conservation. Inhibitors similar to the scenarios discussed earlier in the paper have developed continually at the organizational and industry levels to block decades of initiatives that could have developed into innovations with the power to spawn societal change as broad and sustained as some of the technological changes that have occurred and evolved over the past forty years. Given the public goods nature of environmental sustainability and energy efficiency, what is needed is a prolonged sense of urgency brought about by ongoing turbulence economically, socially, and environmentally, in order to overcome the self-interests of each sector, which so far has had the impact of diluting the collective focus on the interests of society as a whole. Thus:

Proposition 2: Prolonged urgency, undergirded by environmental turbulence affecting the performance of the three sectors, is a necessary condition for forming supraorganizational cross-sectorcollaborations capable of addressing environmental sustainability and energy conservation on a sustained basis.

The unique cultural and institutional characteristics are indicative of the deep-seated barriers toward societal-level change regarding problem domains as broad and pervasive as environmental sustainability and energy conservation. A high degree of urgency, undergirded by turbulent conditions such as sustained fuel shortages, widespread environmental deterioration, and a deep, ongoing economic crisis, appear to be necessary to accept the legitimacy of a bridging organization and make the commitment to accept permanent adjustments in living habits.

\section{Conclusion}

When the lights went off several years ago in the Northeastern U.S., Americans experienced the turbulence that the loss of power caused, and the urgent need to restore power. Americans also recognized how interconnected electrical power is and how easily a problem in one small part of the country can impact millions of citizens, as well as organizational performance, particularly in a financial sector, such as New York City. The media focused on the outdated transmission system in the U.S., and a spate of congressional hearings resulted. However, once the urgency of the issue subsided, other policy priorities took precedence on the congressional agenda and media attention declined. Thus, the prolonged urgency, supported by the ongoing environmental turbulence necessary to address sustainability as an integrated, national imperative, had subsided. The sustainability debate devolved into a collection of special interests advocating for policy action on disparate, often unconnected issues.

Thus, the purpose of this paper has been to identify cross-sector collaboration as an important approach to the problem domain of environmental sustainability and energy conservation, while also analyzing the institutional and cultural differences among the three sectors and the related challenges to successful collaboration. The U.S. is in a critical phase in which the individualistic nature ofAmerican culture, and the manifestation of this culture through rigid, self-interested organizations, inhibits the acceptance of societal mechanisms that can lead to change. Increasingly, it appears that crises are necessary in order to cause sudden bursts of societal responses. Thus, while mechanisms such as cross-sector collaboration hold the potential to support meaningful societal responses to problem domains such as environmental sustainability and energy conservation, urgency, undergirded by ongoing turbulence in our economic, social, and environmental systems, will be needed in order to respond in a sustained manner.

\section{References}

Abrahamson, E., \& Fombrun, C. (1994). Macrocultures: Determinants and consequences. The Academy of Management Review, 19(4), 728-755.

Bertels, S., \& Vredenburg, H. (2004). Broadening the notion of governance from the organization to the domain. The Journal of Corporate Citizenship, 15, 33-47. http://dx.doi.org/10.9774/GLEAF.4700.2004.au.00006

Blois, K. (2004). Analyzing exchanges through the use of value equations. Journal of Business \& Industrial Marketing, 19(4), 250-257. http://dx.doi.org/10.1108/08858620410540982

Cassell, C., \& Symon, G. (1994). Qualitative Methods in Organizational Research. London: Sage.

Cummings, B. (1984). The origins and development of the northeast Asian political economy: Industrial sectors product cycles, and political consequences. International Organization, 381, 1-40. http://dx.doi.org/10.1017/S0020818300004264 
DiMaggio, P. (1983). State expansion and organizational fields. In R. H. Hall \& R. E. Quinn (Eds.), Organizational Theory and Public Policy (pp. 147-161). Beverly Hills, CA: Sage. http://dx.doi.org/10.2307/2095101

DiMaggio, P., \& Powell, W. (1983). The iron cage revisited: Institutional isomorphism and collective rationality in organizational fields. American Sociological Review, 48, 147-160.

Doh, J. P. (2003). Nongovernmental organizations, corporate strategy, and public policy: NGOs as agents of change. In J. P. Doh \& H. Teegen (Eds.), Globalization and NGOs (pp. 1-18). Westport, CT: Praeger.

Downs, A. (1967). Inside Bureaucracy. Boston, MA: Little Brown.

Emery, F., \& Trist, E. (1965). The causal textures of organizational environments. Human Relations, 18, 21-32. http://dx.doi.org/10.1177/001872676501800103

Googins, B. K., \& Rochlin, S. A. (2000). Creating the partnership society: Understanding the rhetoric and reality of cross-sectorpartnerships. Business and Society Review, 105(1), 127-144. http://dx.doi.org/10.1111/0045-3609.00068

Gray, B. (1989). Conditions facilitating interorganizational collaboration. Human Relations, 38, 911-936. http://dx.doi.org/10.1177/001872678503801001

Grimalda, G., \& Sacconi, L. (2005). The constitution of the not-for-profit organization: Reciprocal conformity to morality. Constitutional Political Economy, 16, 249-276. http://dx.doi.org/10.1007/s10602-005-2833-2

Hewitt, J. A., \& Brown, D. K. (2000). Agency costs in environmental non-profits. Public Choice, 103, 163-183. http://dx.doi.org/10.1023/A:1005092819278

Jimenez, A., \& Pasquero, J. (2004). Explaining the endurance of a permanently challenged public-private partnership. Management Research, 3(1), 49.

Knox, S., \& Gruar, C. (2007). The application ofstakeholder theory to relationship marketing strategy development in a non-profit organization. Journalof Business Ethics, 75, 115-135. http://dx.doi.org/10.1007/s10551-006-9258-3

Long, F. J., \& Arnold, M. B. (1995). The Power of Environmental Partnerships. New York: Dryden.

Meyer, J. W., \& Rowan, B. (1977). Institutional organizations: Formal structure as myth and ceremony. American Journal of Sociology, 80, 340-363. http://dx.doi.org/10.1086/226550

Ornstein, N. J., Peabody, R. L., \& Rhode, D. W. (1981). The Contemporary Senate: Into the 1980's'. In L.C. Dodd \& B. I. Oppenheimer (Eds.), Congress Reconsidered. Washington, D.C.: Congressional Quarterly.

Parker, B., \& Selsky, J. (2004). Interface dynamics in cause based partnerships: An exploration of emergent culture. Nonprofit and Voluntary Sector Quarterly, 33(3), 458-488. http://dx.doi.org/10.1177/0899764004266016

Pasquero, J. (1991). Supraorganizational collaboration: The Canadian environmental experiment. Journal of Applied Behavioral Science, 27(1), 38-64. http://dx.doi.org/10.1177/0021886391271003

Radnitzky, G. (1970). Contemporary Schools of Metascience. Gothenburg: Akademieforlaget.

Ring, P. S., \& Perry, J. L. (1985). Strategic management in public and private organizations: Implications of distinctive contexts and constraints. The Academy of Management Review, 10(2), 276-286.

Rondinelli, D. A., \& London, T. (2003). How corporations and environmental groups cooperate: Assessing cross-sector alliances and collaborations. The Academy of Management Executive, 17(1), 61-76. http://dx.doi.org/10.5465/AME.2003.9474812

Scott, W. R., \& Meyer, J. W. (1983). The organization of societal sectors. In J.W. Meyer \& W. R. Scott (Eds.), Organizationalenvironments: Ritual and rationality (pp. 129-153). Beverly Hills, CA: Sage.

Seitandi, M. M., \& Ryan, A. (2007). A critical review of forms of corporate community involvement: From philanthropy to partnerships. International Journal of Nonprofit and Voluntary Sector Marketing, 12(3), 247-267. http://dx.doi.org/10.1002/nvsm.306

Selsky, J. W., \& Parker, B. (2005). Cross-sector partnerships to address social issues: Challenges to theory and practice. Journal of Management, 31(6), 1-25. http://dx.doi.org/10.1177/0149206305279601 
Starik, M., \& Heuer, M. (2002). Strategic inter-organizational environmentalism in the U.S.: A multi-sectoral perspective of alternating eco-policy roles. Business Strategy and the Environment, 11, 221-235. http://dx.doi.org/10.1002/bse.334

Trist, E. L. (1983). Referent organizations and the development of interorganizational domains. Human Relations, 36, 247-268. http://dx.doi.org/10.1177/001872678303600304

Turcotte, M. F., \& Pasquero, J. (2001). The paradox of multistakeholder collaborative roundtables. TheJournal of Applied Behavioral Science, 37(4), 447-464. http://dx.doi.org/10.1177/0021886301374004

Waddock, S. A. (1988). Building successful partnerships.Sloan Management Review. Summer: 17-23.

Waddock, S. A. (1991). A typology of social partnership organizations. Administration\& Society, 22(4), 480-516. http://dx.doi.org/10.1177/009539979102200405

Warner, M., \& Sullivan, R. (2004). Putting partnerships to work: Strategic alliances for development between government and private sector and civil society. Sheffield, UK: Greenleaf Publishing.

Westley, F., \& Vredenburg, H. (1991). Strategic bridging: The collaboration between environmentalists and business in the marketing of green products. Journal of Applied Behavioral Science, 27(1), 65-90. http://dx.doi.org/10.1177/0021886391271004

Westley, F., \& Vredenburg, H. (1997). Interorganizational collaboration and the preservation of global biodiversity.Organization Science, 8(4), 381-403. http://dx.doi.org/10.1287/orsc.8.4.381

\section{Copyrights}

Copyright for this article is retained by the author(s), with first publication rights granted to the journal.

This is an open-access article distributed under the terms and conditions of the Creative Commons Attribution license (http://creativecommons.org/licenses/by/3.0/). 